\title{
EPR and pulsed ENDOR study of intermediates from reactions of aromatic azides with group 13 metal trichlorides
}

\author{
Giorgio Bencivenni ${ }^{1}$, Riccardo Cesari ${ }^{1}$, Daniele Nanni ${ }^{1}$, Hassane El Mkami ${ }^{2}$ \\ and John C. Walton ${ }^{* 3}$
}

\section{Full Research Paper}

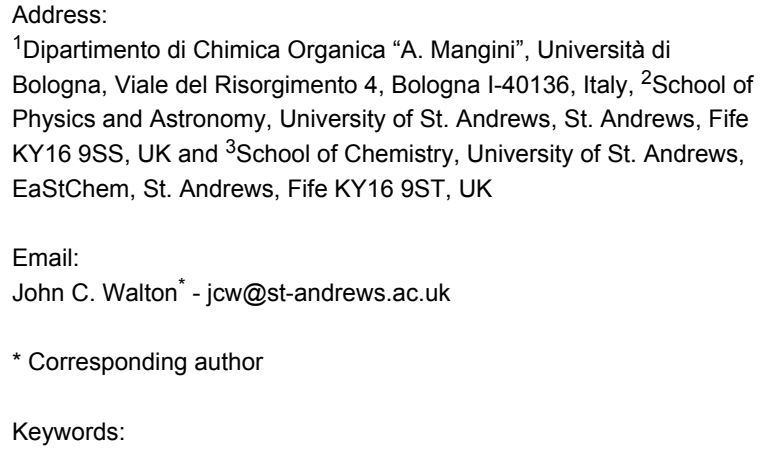

${ }^{1}$ Dipartimento di Chimica Organica "A. Mangini”, Università di Bologna, Viale del Risorgimento 4, Bologna I-40136, Italy, ${ }^{2}$ School of Physics and Astronomy, University of St. Andrews, St. Andrews, Fife KY16 9SS, UK and ${ }^{3}$ School of Chemistry, University of St. Andrews, EaStChem, St. Andrews, Fife KY16 9ST, UK

Email:

John C. Walton* - jcw@st-andrews.ac.uk

* Corresponding author

Keywords:

Beilstein J. Org. Chem. 2010, 6, 713-725. doi:10.3762/bjoc. 6.84

Received: 17 May 2010

Accepted: 23 July 2010

Published: 09 August 2010

Guest Editor: J. Murphy

() 2010 Bencivenni et al; licensee Beilstein-Institut. License and terms: see end of document.

aluminium; aromatic azides; ENDOR; EPR; gallium; indium

\begin{abstract}
The reactions of group 13 metal trichlorides with aromatic azides were examined by CW EPR and pulsed ENDOR spectroscopies. Complex EPR spectra were obtained from reactions of aluminium, gallium and indium trichlorides with phenyl azides containing a variety of substituents. Analysis of the spectra showed that 4-methoxy-, 3-methoxy- and 2-methoxyphenyl azides all gave 'dimer' radical cations $\left[\mathrm{ArNHC}_{6} \mathrm{H}_{4} \mathrm{NH}_{2}\right]^{+\bullet}$ and trimers $\left[\mathrm{ArNHC}_{6} \mathrm{H}_{4} \mathrm{NHC}_{6} \mathrm{H}_{4} \mathrm{NH}_{2}\right]^{+\bullet}$ followed by polymers. 4-Azidobenzonitrile, with its electron-withdrawing substituent, did not react. In general the aromatic azides appeared to react most rapidly with $\mathrm{AlCl}_{3}$ but this reagent tended to generate much polymer. $\mathrm{InCl}_{3}$ was the least reactive group 13 halide. DFT computations of the radical cations provided corroborating evidence and suggested that the unpaired electrons were accommodated in extensive $\pi$-delocalised orbitals. A mechanism to account for the reductive conversion of aromatic azides to the corresponding anilines and thence to the dimers and trimers is proposed.
\end{abstract}

\section{Introduction}

The number of applications of indium [1-6], gallium [7-11] and other group 13 metal derivatives, as promoters of radical reactions, has been increasing ever since the original work of Baba and co-workers with dichloroindium hydride [12-16]. Parallel to that, organic azides are increasingly used as sources of
$\mathrm{N}$-centred radicals, although most such methods also require organotin hydrides [17-23]. In seeking cleaner, less toxic and more efficient synthetic methodology - not reliant on organotin compounds [24-28] - some of us began investigating the reactions of organic azides with dichloroindium hydride [29], 
allylindium dichloride [30], and other group 13 metal derivatives. These reagents smoothly convert aromatic and aliphatic azides into the corresponding amines, $\gamma$-azidonitriles into pyrrolidin-2-imines [29], and $\delta$-azidoesters and chlorides into allylated nitrogen heterocycles [30].

To help in elucidating the mechanisms of these reductions, we used CW EPR spectroscopy and attempted to characterise the reactive intermediates in selected reactions involving gallium trichloride. Surprisingly, we found that treatment of phenyl azide and 4-methoxyphenyl azide with gallium trichloride resulted in strong EPR spectra of long-lived paramagnetic species. By combining the results of product analyses with the results of EPR spectroscopy, we were able to show that persistent radical cations of 'dimers' (4-aminodiphenylamines) and 'trimers' (4'-phenylamino-4-aminodiphenylamines) were being formed [31]. We have now broadened the scope of this investigation to aromatic azides with a range of functionality. We report here our findings on the behaviour of aromatic azides when treated with the group 13 trichlorides of gallium, indium and aluminium.

\section{Results and Discussion Reaction of 4-methoxyphenyl azide (2) with group 13 metal chlorides}

A set of aromatic azides, each containing an electron-releasing or an electron-withdrawing substituent in the 4-position, was chosen for this study. The position of the substituent was also varied and several other azide types were included (Scheme 1). Each organic azide was reacted with the metal halide in dichloromethane/pentane or acetonitrile solution at $\mathrm{rt}$, and an aliquot $(\sim 0.1 \mathrm{~mL})$ was placed in a quartz capillary tube (diam 1 $\mathrm{mm}$ ), purged with nitrogen for $15 \mathrm{~min}$ and transferred to the resonant cavity of an X-band EPR spectrometer. When either $\mathrm{AlCl}_{3}$, or $\mathrm{GaCl}_{3}$ or $\mathrm{InCl}_{3}$ was used, the reaction was accompanied by copious evolution of gas (probably nitrogen) and a

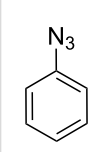<smiles>COc1ccc(N)cc1</smiles>

1<smiles>Nc1ccc(F)cc1</smiles>

6

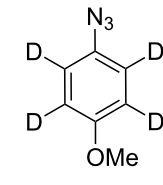

3<smiles>N#[N+]c1ccc2ccccc2c1</smiles>

8<smiles>COc1cccc(N)c1</smiles>

4

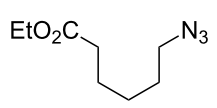

9 deep blue or violet colour usually developed immediately or within a few minutes. In the case of $\mathrm{AlCl}_{3}$ the reactions were very vigorous. Previously, we showed that the main product from the reaction of 4-methoxyphenyl azide 2 with $\mathrm{GaCl}_{3}$ was 4-amino-4'-methoxydiphenylamine (11b, Variamine blue), together with traces of anisole, oxidised derivatives (including 4-(4-methoxyphenylamino)phenol, 4-((4-methoxyphenyl)imino)-cyclohexa-2,5-dienone) and much dark-coloured polymer [31]. The EPR spectrum showed the radical cation of Variamine blue $\left(\mathbf{1 1 b}^{+\bullet}\right)$ plus broad signals which we attributed to oligomer and/or polymer radical cations (Scheme 2).

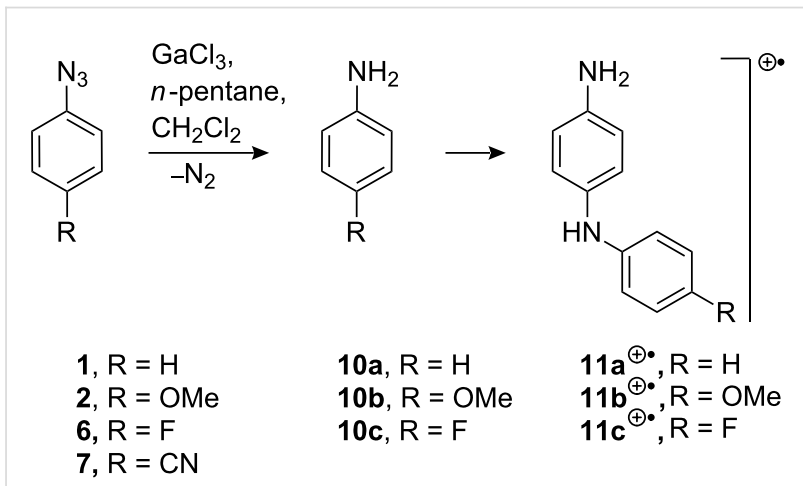

Scheme 2: Reaction of 4-substituted-phenyl azides with $\mathrm{GaCl}_{3}$.

When anhydrous $\mathrm{AlCl}_{3}$ in $\mathrm{DCM}$ - instead of the gallium halide - was added to a solution of azide $\mathbf{2}$, a vigorous reaction took place. The resulting deep-coloured solution was transferred to the EPR spectrometer and initially the spectrum, Figure 1a, was obtained at $300 \mathrm{~K}$. The broad, poorly resolved signal suggested that the mixture was dominated by polymeric material. However, when the solution was cooled down to $220 \mathrm{~K}$, the well-resolved spectrum, Figure 1b, was obtained. The resolution improvement may be due to the fact that most of the polymer separates from the solution at the lower temperature.

A good computer simulation was achieved by utilising the hyperfine splitting constants (hfs) listed in Table 1. A wellresolved EPR spectrum of $\mathbf{1 1 b}^{+\bullet}$, generated from $\mathbf{2}$ with $\mathrm{GaCl}_{3}$, is shown in Figure 1c for comparison. Figure 1d shows the experimental spectrum obtained from treatment of $\mathbf{2}$ with $\mathrm{InCl}_{3}$, together with the corresponding computer simulation. Although the three EPR spectra appear different at first sight, the hfs derived from the simulations (Table 1) are actually quite similar. The contrasts in the spectral appearances are mainly the result of different line widths with consequently different resolutions. It is evident that the main species in each case is the radical cation $\mathbf{1 1 b ^ { + \bullet }}$. The acceptable agreement between the DFT-computed isotropic hfs of $\mathbf{1 1} \mathbf{b}^{+\bullet}$ (Table 1) and the experimental data provides additional support for this identification. 


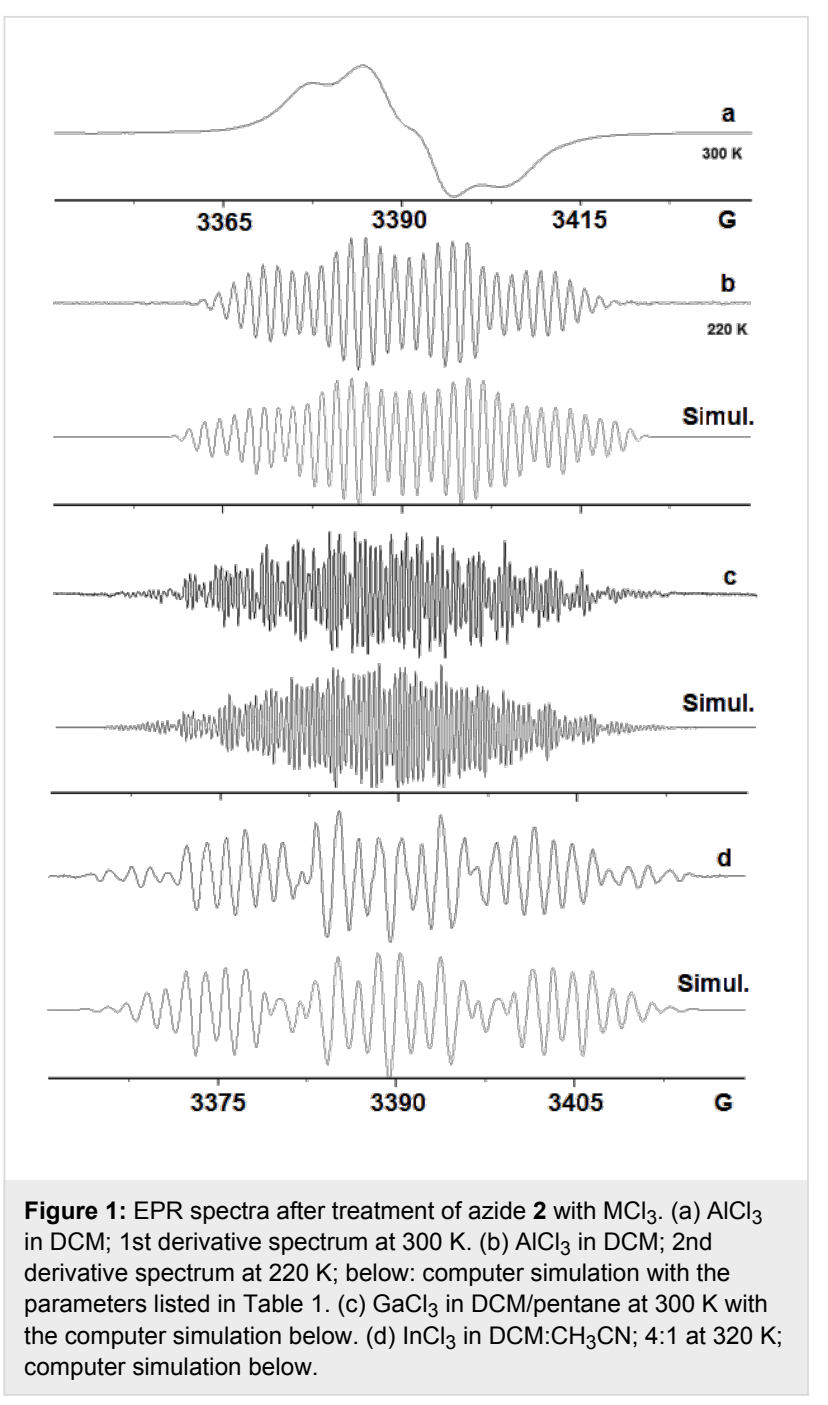

The small differences in the hfs obtained for the different group 13 metal chlorides can probably be attributed to the different counter ions, solvents and temperatures.

The 4-methoxy-tetradeuterio-azide 3 was also treated with $\mathrm{AlCl}_{3}$ in $\mathrm{DCM}$, and the resulting spectrum and simulation are shown in Figure 2.

The unpaired electron interacts with two non-equivalent $\mathrm{N}$-atoms, a single comparatively large $\mathrm{H}$-atom and a pair of equivalent $\mathrm{H}$-atoms. The spectrum obtained previously on treatment of 3 with $\mathrm{GaCl}_{3}$ was better resolved (Table 1) [31]. However, it is clear that the same 'dimer' species was formed with $\mathrm{AlCl}_{3}$, probably having picked up the $\mathrm{NH}$ and $\mathrm{NH}_{2}$ hydrogen atoms from the solvent. The line width of the spectrum with $\mathrm{AlCl}_{3}$ was ca. $0.7 \mathrm{G}$. Therefore, it is not surprising that hfs from aromatic ring D-atoms were not resolved. Again, differences in the hfs of the spectra from $\mathrm{AlCl}_{3}$ and $\mathrm{GaCl}_{3}$ can be attributed to the different counter ions.

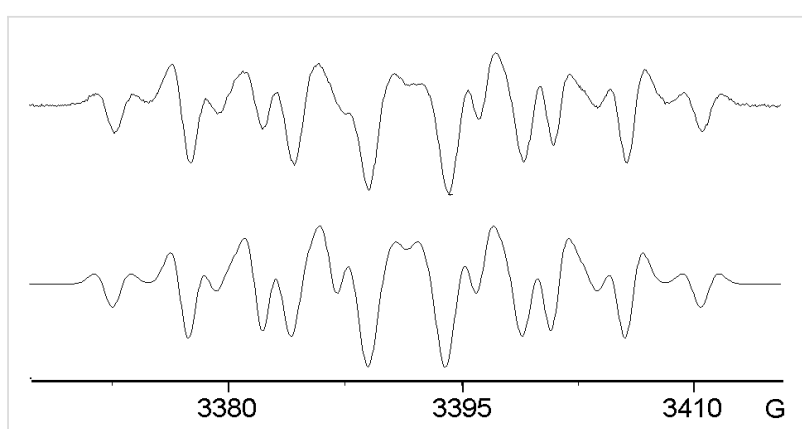

Figure 2: EPR spectrum after treatment of tetra-deuterated azide 3 with $\mathrm{AlCl}_{3}$. Top: 2 nd derivative spectrum at $290 \mathrm{~K}$ in DCM. Bottom: computer simulation using the hfs from Table 1.

\section{Reactions of phenyl azide and 4-substituted- phenyl azides with group 13 metal chlorides}

Azides 1, 6 and 7 were chosen to vary the electronic properties and leaving group abilities of 4-substituents. We showed previously that treatment of phenyl azide 1 with $\mathrm{GaCl}_{3}$ gave well-resolved spectra of 4-aminodiphenylamine radical cation $\left(\mathbf{1 1 a}^{+} \cdot\right.$, the dimer) and of the trimer under different reaction conditions [31]. On treatment with $\mathrm{InCl}_{3}, 1$ gave little sign of reaction. No colour developed and no EPR spectra were obtained. However, a vigorous reaction took place between $\mathbf{1}$ and $\mathrm{AlCl}_{3}$ with nitrogen evolution and development of a deep blue colour. The EPR spectrum, Figure 3a, was dominated by a broad component, probably due to polyaniline type material, together with some fine structure. The second derivative spectrum at low modulation amplitude discriminated against the broad signal, and spectrum, Figure $3 \mathrm{~b}$, was obtained after digitally removing the residual broad component.

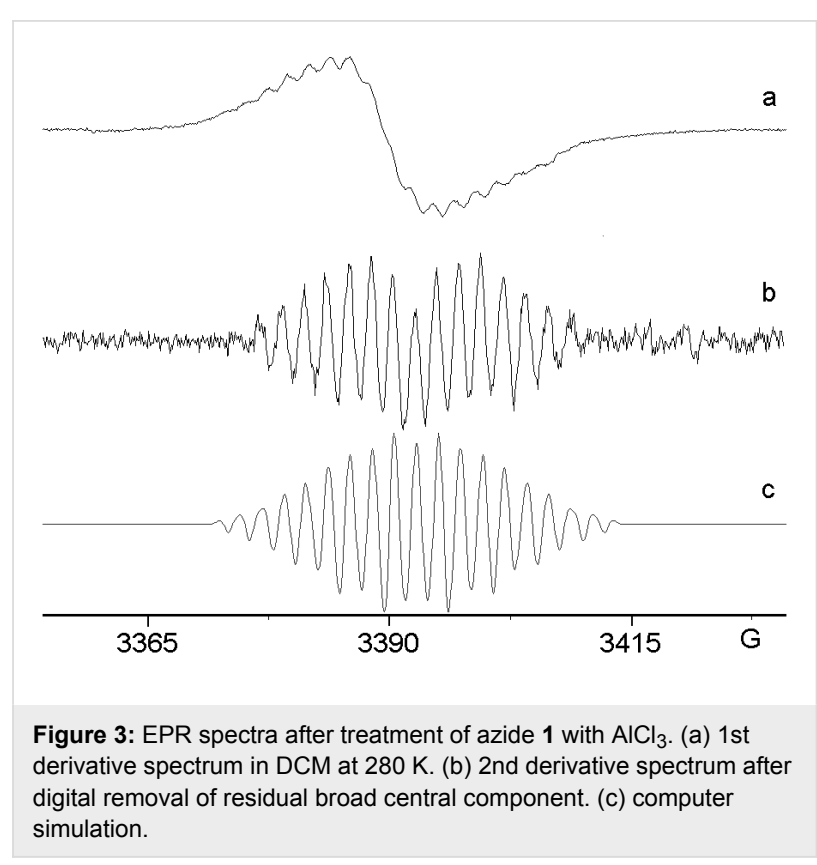




\begin{tabular}{|c|c|c|c|c|c|c|c|c|c|c|c|}
\hline Precursor & $\mathrm{MCl}_{3} /$ solvent & $\begin{array}{l}\text { Radical } \\
\text { cation } \\
\text { species }\end{array}$ & $1 \mathrm{~N}$ & $1 \mathrm{~N}$ & $(\mathrm{~N}) \mathrm{H}$ & $(\mathrm{N}) \mathrm{H}_{2}$ & $2 \mathrm{H}$ & $2 \mathrm{H}$ & $2 \mathrm{H}$ & $2 \mathrm{H}$ & Other \\
\hline$\underset{1^{\mathrm{b}}}{\mathrm{PhN}_{3}}$ & $\mathrm{GaCl}_{3} / \mathrm{DCM}$ & $11 a^{+\bullet}$ & 4.9 & 4.9 & 6.8 & 5.6 & 3.1 & 2.0 & 1.0 & 0.6 & $\begin{array}{l}1 \mathrm{H} \\
1.0\end{array}$ \\
\hline $\begin{array}{c}\mathrm{PhN}_{3} \\
1\end{array}$ & $\begin{array}{c}\mathrm{AlCl}_{3} / \mathrm{DCM} \\
\mathrm{ACN}\end{array}$ & $11 a^{+\bullet}$ & 4.5 & 4.5 & 6.3 & 5.0 & 2.2 & & & & \\
\hline $\begin{array}{c}\mathrm{PhN}_{3} \\
1\end{array}$ & $\mathrm{DFT}^{\mathrm{C}}$ & $11 \mathrm{a}^{+\bullet}$ & 4.3 & 2.2 & -8.4 & -4.8 & -2.0 & -1.8 & -1.1 & 1.0 & $\begin{array}{l}1 \mathrm{H} \\
-2.3\end{array}$ \\
\hline$\underset{2}{4-\mathrm{MeOC}_{6} \mathrm{H}_{4} \mathrm{~N}_{3}}$ & $\mathrm{AlCl}_{3} / \mathrm{DCM}$ & $11 b^{+\bullet}$ & 4.9 & 4.3 & 7.3 & 3.7 & 1.2 & 1.2 & & & \\
\hline$\underset{2^{\mathrm{d}}}{4-\mathrm{MeOC}_{6} \mathrm{H}_{4} \mathrm{~N}_{3}}$ & $\mathrm{GaCl}_{3} / \mathrm{DCM}$ & $11 b^{+\bullet}$ & 5.2 & 4.4 & 7.3 & 3.8 & 3.1 & 2.2 & 0.8 & 0.4 & \\
\hline$\underset{2}{4-\mathrm{MeOC}_{6} \mathrm{H}_{4} \mathrm{~N}_{3}}$ & $\begin{array}{c}\mathrm{InCl}_{3} / \mathrm{DCM} 4 \\
\mathrm{ACN} 1\end{array}$ & $11 b^{+\bullet}$ & 5.2 & 4.0 & 7.8 & 3.2 & 3.2 & 3.2 & 1.8 & & \\
\hline$\underset{2}{4-\mathrm{MeOC}_{6} \mathrm{H}_{4} \mathrm{~N}_{3}}$ & $\mathrm{DFT}^{\mathrm{C}}$ & $11 b^{+\bullet}$ & 4.2 & 2.0 & -8.1 & -4.4 & $-2.0,-1.6$ & $-1.6,-1.4$ & -0.8 & 0.2 & $\begin{array}{c}\mathrm{MeO}, \\
1.2\end{array}$ \\
\hline$\underset{\mathbf{3}}{4-\mathrm{MeOC}_{6} \mathrm{D}_{4} \mathrm{~N}_{3}}$ & $\mathrm{AlCl}_{3} / \mathrm{DCM}$ & & 5.9 & 4.8 & 6.7 & 4.9 & - & - & - & - & \\
\hline$\underset{3^{\mathrm{d}}}{4-\mathrm{MeOC}_{6} \mathrm{D}_{4} \mathrm{~N}_{3}}$ & $\mathrm{GaCl}_{3} / \mathrm{DCM}$ & & 5.2 & 4.4 & 7.1 & 3.6 & $0.66,2 \mathrm{D}$ & $0.55,2 \mathrm{D}$ & & & \\
\hline$\underset{4}{3-\mathbf{M e O P h N}_{3}}$ & $\mathrm{GaCl}_{3} / \mathrm{ACN}$ & $17 \mathrm{a}^{+\bullet}$ & 4.3 & - & 5.7 & $5.2,5.2$ & $5.7,5.7$ & $5.2,5.7$ & - & - & \\
\hline$\underset{4}{3-\mathrm{MeOPhN}_{3}}$ & $\mathrm{DFT}^{\mathrm{C}}$ & $17 a^{+\bullet}$ & 3.8 & 1.1 & -7.6 & $-2.3,-2.0$ & $-7.2,-7.3$ & $2.6,-3.4$ & $-2.3,1.3$ & $-0.9,-0.2$ & $\begin{array}{l}\mathrm{MeO} \\
-0.1\end{array}$ \\
\hline$\underset{\mathbf{5}}{2-\mathrm{MeOC}_{6} \mathrm{H}_{4} \mathrm{~N}_{3}}$ & $\mathrm{GaCl}_{3} / \mathrm{DCM}$ & $17 b^{+\bullet}$ & 4.1 & 4.1 & 5.5 & 5.5 & & & & & \\
\hline$\underset{\mathbf{5}}{2-\mathrm{MeOC}_{6} \mathrm{H}_{4} \mathrm{~N}_{3}}$ & $\mathrm{DFT}$ & $17 b^{+\bullet}$ & 4.0 & 1.5 & -8.1 & -3.9 & $-3.1,-2.3$ & $-1.5,-1.6$ & $0.8,0.7$ & $-0.3,0.1$ & $\begin{array}{c}\mathrm{MeO}, \\
0.8\end{array}$ \\
\hline$\underset{6}{4-\mathrm{FC}_{6} \mathrm{H}_{4} \mathrm{~N}_{3}}$ & $\begin{array}{c}\mathrm{HGaCl}_{2} / \mathrm{ACN} \\
\mathrm{TES}^{\mathrm{e}}\end{array}$ & $11 \mathrm{c}^{+\bullet}$ & 4.4 & 3.9 & 4.0 & 4.0 & 2.0 & 2.0 & 1.0 & 0.5 & $\begin{array}{l}1 \mathrm{~F} \\
6.6\end{array}$ \\
\hline $\begin{array}{c}4-\mathrm{FC}_{6} \mathrm{H}_{4} \mathrm{~N}_{3} \\
\mathbf{6}\end{array}$ & $\mathrm{DFT}^{\mathrm{c}}$ & $11 \mathrm{c}^{+\bullet}$ & 4.0 & 2.5 & -7.9 & -5.5 & -1.7 & -1.4 & -1.4 & 0.5 & $4.3^{f}$ \\
\hline $\begin{array}{c}\text { 2- } \mathrm{NapN}_{3} \\
\mathbf{8}\end{array}$ & $\begin{array}{c}\mathrm{InCl}_{3} / \mathrm{DCM} 4 \\
\mathrm{ACN} 1\end{array}$ & & 3.4 & 3.4 & 5.6 & 2.8 & $2.8(1 \mathrm{H})$ & & & & \\
\hline $\begin{array}{l}\text { aAll g-factors were } \\
\text { magnitudes and no } \\
\text { b Treatment of } \mathrm{PhN}_{3} \\
{ }^{\mathrm{c}} \mathrm{DFT} \text { computations } \\
{ }^{\mathrm{d} D a t a} \text { from ref [31]. } \\
\text { e } \mathrm{H}_{\mathrm{H} a \mathrm{C}} \text { prepared } \\
\text { basis set. }\end{array}$ & $\begin{array}{l}2.0032 \pm 0.0005 \text {. } \\
\text { the signs of hfs } \\
3 \text { and } 3-\mathrm{MeOC}_{6} \mathrm{H}_{4} \\
\text { : geometries optin } \\
\text { from } \mathrm{GaCl}_{3} \text { and } \mathrm{E}\end{array}$ & $\begin{array}{l}\text { Assignment } \\
\text { an be deriv } \\
\mathrm{N}_{3} \text { with } \mathrm{InC} \\
\text { iised to UB } \\
{ }_{3} \mathrm{SiH} \text { (TES) }\end{array}$ & $\begin{array}{l}\text { ts of hf } \\
\text { ved fro } \\
\mathrm{Cl}_{3} \text { gave } \\
3 \text { LYP/ } \\
\text { ). }{ }^{\text {TThe }}\end{array}$ & $\begin{array}{l}\text { fs to } \\
\text { om the } \\
\text { e onl } \\
\text { /6-31 } \\
\text { com }\end{array}$ & $\begin{array}{l}\text { EPR spe } \\
\text { very we } \\
\text { E(d,p) th } \\
\text { ted } a(F\end{array}$ & $\begin{array}{l}\text { oms are tentat } \\
\text { ctra. } \\
\text { k and broad } 4 \\
\text { en single poin } \\
\text { varied from } 4\end{array}$ & $\begin{array}{l}\text { ive and are ba } \\
\text { unresolved spe } \\
\text { t calculations } \\
\\
.3 \mathrm{G} \text {, with the }\end{array}$ & $\begin{array}{l}\text { ased on the DF } \\
\text { ectra. } \\
\text { with } 6-311++G \\
6-311++G(d, p\end{array}$ & d,p) basis. & $9.5 \mathrm{G}$ with $\mathrm{t}$ & DGDZVP \\
\hline
\end{tabular}

The hfs were similar to those of $\mathbf{1 1 a}^{+\bullet}$ (Table 1, entry for $\mathbf{1}$ with $\mathrm{GaCl}_{3}$ ) except that the smaller hfs were not resolved. Minor differences in the magnitudes of the hfs can be attributed to the different counter ions. The trimer radical cation was not observed, but clearly a contribution from this species could be hidden under the broad component.

No reaction of 4-azidobenzonitrile 7 with $\mathrm{InCl}_{3}, \mathrm{GaCl}_{3}$ or $\mathrm{AlCl}_{3}$ was observed and no paramagnetic species were detected by EPR spectroscopy. It appears the electron-accepting property of the $\mathrm{CN}$ group inhibited the coupling process at some stage. It is also worth mentioning that, as expected, aliphatic azides such as ethyl 5-azidopentanoate 9 did not react in the same way either. Treatment of 9 with $\mathrm{InCl}_{3}$ or $\mathrm{GaCl}_{3}$ led to gas evolution but no colour developed and no paramagnetic species could be detected.

Very interesting results were obtained from reactions of 1-azido-4-fluorobenzene (6). When 6 was treated with $\mathrm{GaCl}_{3}$ in DCM, a deep blue-violet colour developed and the spectrum was dominated by a broad feature, Figure 4a, although underlying fine structure was evident. When dichlorogallium hydride, prepared from $\mathrm{GaCl}_{3}$ and $\mathrm{Et}_{3} \mathrm{SiH}$ in $\mathrm{CH}_{3} \mathrm{CN}$, was used to promote the reaction, a beautifully resolved spectrum resulted, Figure $4 b$.

The good simulation of this spectrum, Figure $4 \mathrm{c}$, enabled the hfs shown in Table 1 to be determined. Comparison of these hfs 


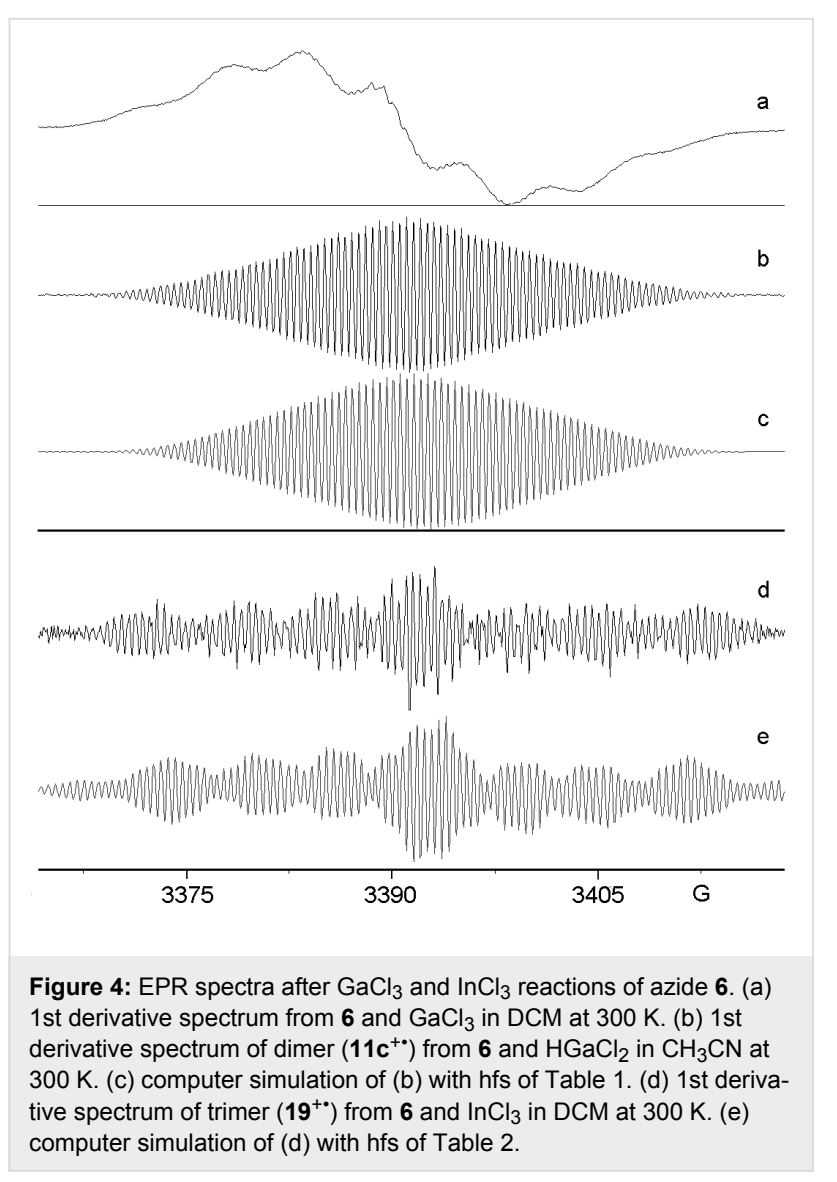

with those of the other species in Table 1 supports the identification of this intermediate as the corresponding dimer cation $\mathbf{1 1} \mathbf{c}^{+\bullet}$, containing a single F-atom. The DFT computation on the dimer hfs gave satisfactory agreement (Table 1), with the possible exception of the para-F hfs. However, DFT-computed $a(F)$ values varied from 7.2 , to 7.1 , to 9.5 and $4.3 \mathrm{G}$ with 6-31G(d), 6-31+G(d,p), DGDZVP and 6-311++G(d,p) basis sets, respectively. This spread indicates the comparative unreliability of the DFT spin density computations for F-atoms in these cations.

Treatment of $\mathbf{6}$ with $\mathrm{InCl}_{3}$ in DCM led to the usual broad signal from oligomeric and polymeric species superimposed on a spectrum with much narrower lines. On recording the spectrum with a smaller modulation amplitude, and digitally removing the residual broad feature, the spectrum shown in Figure 4d resulted. This is obviously a different species from that of Figure $4 \mathrm{~b}$ and, after many trials, a satisfactory simulation was obtained, Figure 4e. The derived hfs are presented in Table 2 and they clearly correspond to a trimer, also probably containing a single F-atom, i.e. $\mathbf{1 9 b}^{+\bullet}$.

It seems clear that the $\mathrm{MCl}_{3}$ reactions with aromatic azides entail a progression from the aniline $\mathrm{XC}_{6} \mathrm{H}_{4} \mathrm{NH}_{2}$, to the dimer
$\mathrm{XC}_{6} \mathrm{H}_{4} \mathrm{NHC}_{6} \mathrm{H}_{4} \mathrm{NH}_{2}$, to the trimer $\mathrm{XC}_{6} \mathrm{H}_{4} \mathrm{NHC}_{6} \mathrm{H}_{4} \mathrm{NH}-$ $\mathrm{C}_{6} \mathrm{H}_{4} \mathrm{NH}_{2}$, thence to oligomers and eventually polyaniline type polymers $\mathrm{X}\left[\mathrm{C}_{6} \mathrm{H}_{4} \mathrm{NH}\right]_{n} \mathrm{C}_{6} \mathrm{H}_{4} \mathrm{NH}_{2}$. Some polymer radical cation was always observed by EPR spectroscopy, but whether dimer or trimer or oligomer dominated the spectrum depended on a delicate balance between solvent, metal halide and other factors.

\section{Reactions of 2-methoxy- and 3-methoxyphenyl azides with group 13 metal chlorides}

Aromatic azides $\mathbf{4}$ and $\mathbf{5}$ were chosen to investigate how the position of the $\mathrm{MeO}$ substituent influenced the reaction. Treatment of the 3-methoxy precursor 4 with $\mathrm{InCl}_{3}$ or $\mathrm{HInCl}_{2}$ gave only very weak and broad EPR spectra. However, reaction of $\mathbf{4}$ with $\mathrm{GaCl}_{3}$ in $\mathrm{CH}_{3} \mathrm{CN}$ gave a strong EPR spectrum and the hfs derived from the computer simulation are presented in Table 1. The comparatively large line width $(\sim 0.9 \mathrm{G})$ did not permit the resolution of small hfs from aromatic ring $\mathrm{H}$-atoms. For the same reason, the hfs from the second $\mathrm{N}$-atom were not resolved. However, it is clear that this species is probably a 'dimer' although the connectivity of the angular structure $\mathbf{1 7 \mathbf { a } ^ { + \bullet }}$ is somewhat different from that of the 4-aminodiphenylamines derived from the 4-substituted phenyl azides (Scheme 3 ).

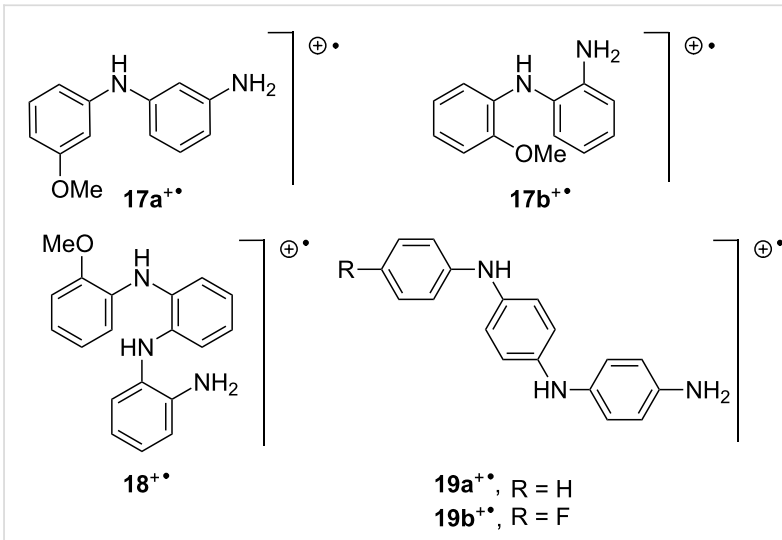

Scheme 3: Dimer and trimer radical cations.

Treatment of the 2-methoxy precursor 5 with $\mathrm{GaCl}_{3}$ in DCM, or with $\mathrm{HGaCl}_{2}$ in $\mathrm{CH}_{3} \mathrm{CN}$, gave essentially the same strong spectrum, see Figure 5a and Supporting Information. The hfs derived from the simulations (Table 1) suggest that this is also a dimer type radical cation $\mathbf{1 7} \mathbf{b}^{+\bullet}$. However, with the passage of time a central peak began to appear in this spectrum. When $\mathbf{5}$ was treated with $\mathrm{HGaCl}_{2}$, prepared from $\mathrm{GaCl}_{3}$ and $\mathrm{Et}_{3} \mathrm{SiH}$, the species with a central peak dominated the spectrum, Figure $5 \mathrm{~b}$. Treatment of 5 with $\mathrm{InCl}_{3}$ in DCM or with $\mathrm{HInCl}_{2}$ in THF (prepared from $\mathrm{InCl}_{3}$ and DIBAL-H) also gave rise to a spectrum of this same species, Figure 5c. A well-resolved spectrum of this species was obtained by treatment of 5 with 
Table 2: EPR hfs of 'trimer' species $\left\{[\mathrm{ArNH}]_{2} \mathrm{C}_{6} \mathrm{H}_{4} \mathrm{NH}_{2}\right\}^{+\cdot}$ from treatment of aryl azides with group 13 metal chlorides. ${ }^{\text {a }}$

\begin{tabular}{|c|c|c|c|c|c|c|c|c|c|c|}
\hline Precursor & $\begin{array}{c}\mathrm{MCl}_{3} / \text { solvent or } \\
\text { DFT }\end{array}$ & $\begin{array}{l}\text { Trimer } \\
\text { radical } \\
\text { cation }\end{array}$ & $\mathrm{N}$ & $\mathrm{N}$ & $\mathrm{N}\left(\mathrm{H}_{2}\right)$ & $(\mathrm{N}) \mathrm{H}_{2}$ & $(\mathrm{~N}) \mathrm{H}$ & $(\mathrm{N}) \mathrm{H}$ & H-rings & Other \\
\hline$\underset{\mathbf{1}^{\mathbf{b}}}{\mathrm{PhN}_{3}}$ & $\mathrm{GaCl}_{3} / \mathrm{DCM}$ & $19 \mathrm{a}^{+\bullet}$ & 5.0 & 4.9 & 3.0 & 6.5 & 4.9 & 2.1 & $\begin{array}{l}2.1(3 \mathrm{H}) \\
1.0(3 \mathrm{H})\end{array}$ & \\
\hline $\begin{array}{c}\mathrm{PhN}_{3} \\
1\end{array}$ & $\mathrm{DFT}^{\mathrm{C}}$ & $19 a^{+\cdot}$ & 5.4 & 3.4 & 2.0 & -3.0 & -7.8 & -4.8 & $\begin{array}{r}-1.6(4 \mathrm{H}) \\
-1.0(3 \mathrm{H}) \\
< \pm 0.6(6 \mathrm{H})\end{array}$ & \\
\hline $\begin{array}{c}4-\mathrm{FC}_{6} \mathrm{H}_{4} \mathrm{~N}_{3} \\
\mathbf{6}\end{array}$ & $\mathrm{InCl}_{3} / \mathrm{DCM}$ & $19 b^{+\cdot}$ & 5.5 & 5.5 & 2.6 & 6.2 & 7.2 & 4.5 & $\begin{array}{l}2.2(1 \mathrm{H}) \\
1.5(2 \mathrm{H}) \\
0.5(6 \mathrm{H})\end{array}$ & $2.2(1 \mathrm{~F})$ \\
\hline $\begin{array}{c}4-\mathrm{FC}_{6} \mathrm{H}_{4} \mathrm{~N}_{3} \\
\mathbf{6}\end{array}$ & $\mathrm{DFT}^{\mathrm{d}}$ & $19 b^{+\cdot}$ & 3.7 & 2.1 & 1.5 & -3.2 & -7.2 & -4.2 & $\begin{array}{l}-1.3(4 \mathrm{H}) \\
-0.6(4 \mathrm{H}) \\
<0.6(4 \mathrm{H})\end{array}$ & $1.5(1 \mathrm{~F})$ \\
\hline$\underset{\mathbf{5}}{2-\mathrm{MeOC}_{6} \mathrm{H}_{4} \mathrm{~N}_{3}}$ & $\mathrm{InCl}_{3} / \mathrm{DCM}$ & $18^{+\bullet}$ & 4.8 & 4.8 & 4.8 & 5.1 & 5.1 & 5.1 & - & \\
\hline$\underset{\mathbf{5}}{2-\mathrm{MeOC}_{6} \mathrm{H}_{4} \mathrm{~N}_{3}}$ & $\mathrm{HGaCl}_{2} \mathrm{e} / \mathrm{CN}$ & $18^{+\cdot}$ & 4.5 & 4.5 & 3.0 & $\begin{array}{l}4.1 \\
1.7\end{array}$ & 5.5 & 5.5 & $\begin{array}{l}1.7(1 \mathrm{H}) \\
0.5(4 \mathrm{H})\end{array}$ & \\
\hline$\underset{\mathbf{5}}{2-\mathrm{MeOC}_{6} \mathrm{H}_{4} \mathrm{~N}_{3}}$ & $\mathrm{DFT}^{\mathrm{C}}$ & $18^{+\cdot}$ & 4.4 & 3.9 & 1.5 & $\begin{array}{l}-2.0 \\
-1.6\end{array}$ & -6.6 & -5.1 & $\begin{array}{l}-2.0(1 \mathrm{H}) \\
-1.7(2 \mathrm{H}) \\
-1.1(1 \mathrm{H}) \\
<0.7(8 \mathrm{H})\end{array}$ & $\begin{array}{c}0.4 \\
\left(\mathrm{CH}_{3} \mathrm{O}\right)\end{array}$ \\
\hline
\end{tabular}

${ }^{\text {aAll }}$ g-factors $2.0032 \pm 0.0005$, assignments of hfs to specific atoms are tentative and are based on the DFT computations. Note that only the magnitudes and not the signs of hfs can be derived from the EPR spectra. ' $D$ ata from ref [31]. 'DFT: UB3LYP/6-31G(d). dDFT computations: UB3LYP/6$31+G(d, p)$ then single point calculation with 6-311++G(d,p) basis. ${ }^{e} \mathrm{HGaCl}_{2}$ prepared from $\mathrm{GaCl}_{3}$ and $\mathrm{Et}_{3} \mathrm{SiH}$ (TES).

$\mathrm{HGaCl}_{2}$ prepared with $\mathrm{Et}_{3} \mathrm{SiH}$ in $\mathrm{CH}_{3} \mathrm{CN}$, Figure $5 \mathrm{~d}$. The hfs derived from the computer simulation, Figure $5 \mathrm{e}$ and Table 2 show the presence of three $\mathrm{N}$-atoms and of four $\mathrm{H}$-atoms with sizeable hfs that can probably be attributed to $\mathrm{NH}$ or $\mathrm{NH}_{2}$ groups. Thus, this species is almost certainly a 'trimer' although this will necessarily have an angular structure $\mathbf{1 8}^{+\bullet}$ rather than the linear type structure of the trimers from 4 -subsitituted azides such as $\mathbf{1 9}^{+\bullet}$ (Scheme 3).

The results from azides $\mathbf{4}$ and $\mathbf{5}$ showed that the position of the $\mathrm{MeO}$ substituent in the phenyl azides was not critical. The reactions with gallium and indium promoters proceeded along similar lines to that of phenyl and 4-substituted phenyl azides to give dimers, trimers and polymers.

The spectra obtained on treatment of 2-azidonaphthalene 8 with $\mathrm{InCl}_{3}, \mathrm{GaCl}_{3}$ and $\mathrm{AlCl}_{3}$ are shown in Figure $6 \mathrm{a}$, Figure $6 \mathrm{~b}$ and Figure 6c, respectively.

The broad signal in Figure 6c shows that polymerisation dominated the reaction with $\mathrm{AlCl}_{3}$. Similarly, the main broad feature in Figure $6 \mathrm{~b}$ suggests that polymerisation was again dominant in the reaction with $\mathrm{GaCl}_{3}$. The comparatively well-resolved species observed in the $\mathrm{InCl}_{3}$-promoted reaction, Figure 6a, was well simulated on using the parameters shown in Table 1 . The data show that the unpaired electron interacted with two

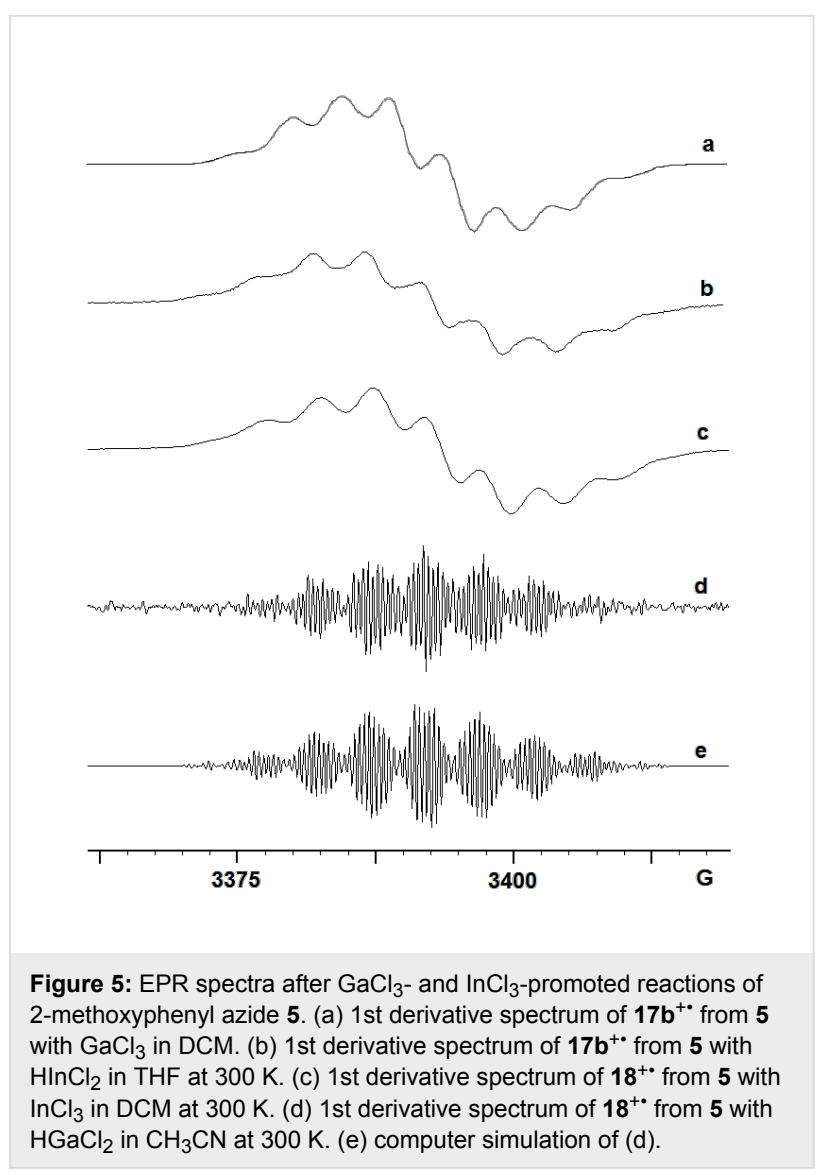




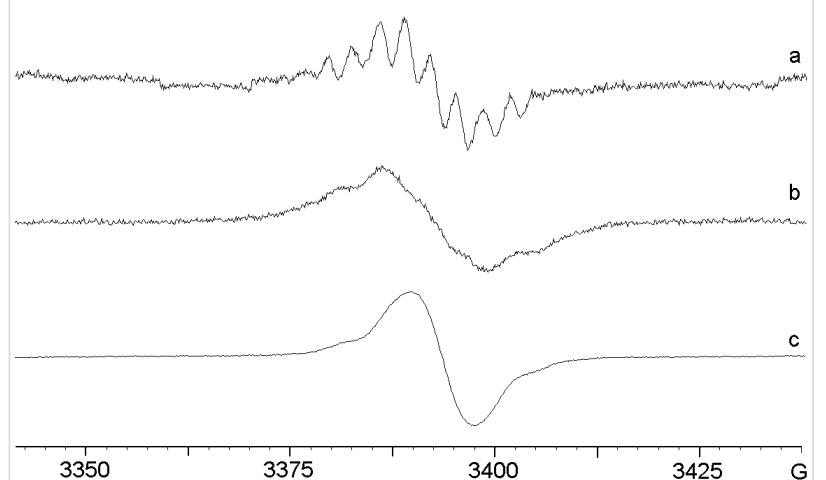

Figure 6: EPR spectra after In-, Ga- and Al-promoted reactions of azide 8. (a) intermediate from $\mathrm{InCl}_{3}$ treatment of 8 at $260 \mathrm{~K}$ in DCM and $\mathrm{CH}_{3} \mathrm{CN}$ (4:1). (b) spectrum from $\mathrm{GaCl}_{3}$ treatment of 8 at $300 \mathrm{~K}$ in $\mathrm{DCM} /$ pentane. (c) spectrum from $\mathrm{AlCl}_{3}$ treatment of 8 at $300 \mathrm{~K}$ in DCM.

$\mathrm{N}$-atoms, two $(\mathrm{N}) \mathrm{H}_{2}$ atoms, one $(\mathrm{N}) \mathrm{H}$-atom and one other $\mathrm{H}$-atom; other splittings were not resolved. The magnitudes of the hfs are somewhat smaller than those of analogous atoms in the dimer from $\mathbf{1}$. This is exactly as would be expected from the greater extent of aromatic delocalisation in a dimer from $\mathbf{8}$ Clearly, however, more than one isomer is possible.

\section{Pulse ENDOR spectrum of the intermediate from 4-fluorophenyl azide 6}

Pulsed ENDOR experiments, based on the ESE effect, were carried out on the frozen solution from azide 6 at $50 \mathrm{~K}$. The echo signal was created by the microwave pulse sequence, and an rf pulse was applied during the 'mixing period', which corresponded to the time $T$ in the Davies ENDOR sequence [32]. The rf pulse drove the nuclear spin transitions, which led to a change in the ESE intensity. The ENDOR signal was therefore measured by monitoring the ESE intensity while the rf frequency was varied. In the case of an $S=1 / 2$ system coupled with a nucleus with nuclear $\operatorname{spin} I=1 / 2$, the Davies ENDOR spectrum consists of two lines at the nuclear resonance frequencies $v_{\alpha}$ and $v_{\beta}$, which correspond to the transitions associated with the electron spin manifolds $M_{\mathrm{S}}=+1 / 2$ and $M_{\mathrm{S}}=-1 / 2$, respectively. If the Larmor frequency $\left(v_{n}\right)$ of the nucleus in question is larger than the hyperfine interaction, then the resonance frequencies are given by:

$$
v_{\alpha \beta}=\left|v_{\mathrm{n}} \pm 1 / 2 a_{\text {iso }}\right| \text {. }
$$

If $v_{\mathrm{n}}$ is less than $1 / 2 a_{\text {iso }}$, the frequencies are then given by:

$$
v_{\alpha \beta}=\left|1 / 2 a_{\text {iso }} \pm v_{\mathrm{n}}\right| .
$$

An additional complication arises if the nuclear spin is $>1 / 2$, which adds another term describing the nuclear quadrupole interaction in the above equations [33]. In frozen solution all orientations of the paramagnetic species are observed and therefore an anisotropic ENDOR spectrum is expected. The latter is more complex and requires a detailed understanding of the anisotropy of the system. The above equations are not suitable for such a situation and a more complete resonance condition that considers all the orientations is needed. In the case of a system with $I=1 / 2$ the parameter $a_{\text {iso }}$ in Equation 1 and Equation 2 is replaced by $A_{\mathrm{i}}$ (i.e. one of the principal components of the hyperfine tensor).

The Davies ENDOR spectrum from the species derived from the 4-fluoroazide 6 sample at $50 \mathrm{~K}$ is shown in Figure 7. The inset shows the ESE-EPR spectrum, with an arrow indicating the magnetic field position at which the ENDOR experiment was performed. The ENDOR spectrum shows powder pattern lineshapes, as expected for frozen solutions, due to the anisotropic hyperfine interactions. Two main features cover the whole spectrum; a powder pattern centred about the ${ }^{1} \mathrm{H}$ Larmor frequency and a second broad signal located at lower frequency and spread over $8 \mathrm{MHz}$ width.

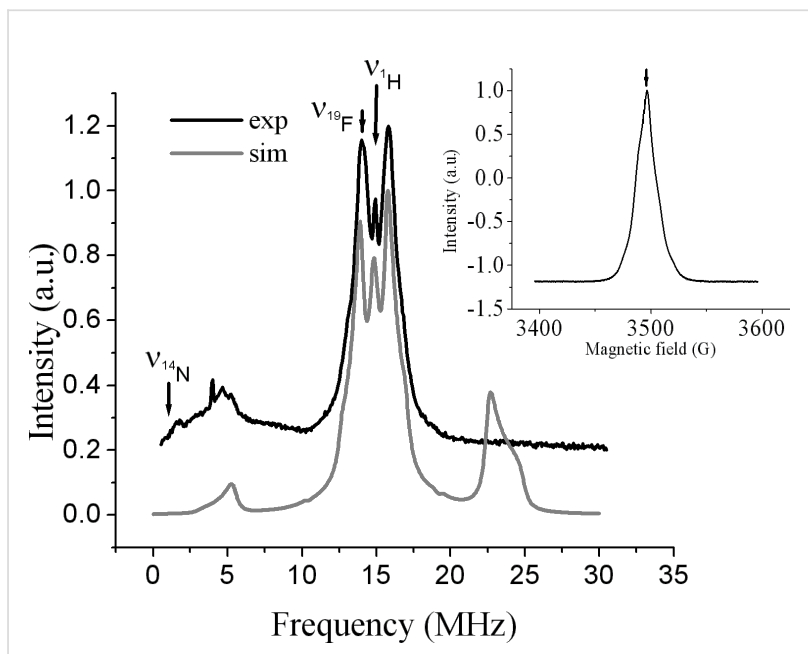

Figure 7: Experimental and simulated Davies ENDOR spectrum after the Ga-promoted reaction of azide 6 recorded at $50 \mathrm{~K}$. The inset shows the field-swept EPR spectrum with an arrow indicating the magnetic field position of the ENDOR experiment.

The lack of resolution encountered in the ENDOR spectrum makes an unequivocal analysis difficult. Therefore, our ENDOR simulation was based mainly on the CW EPR results. A simulated spectrum is displayed in Figure 7, and a deconvoluted version is in the Supporting Information together with one chosen set of ENDOR hyperfine tensor parameters. Almost all the ${ }^{1} \mathrm{H}$ hyperfine splittings fit well within the ENDOR spectra, 
but it is worth noting, as mentioned above, that a satisfactory simulation was only achieved by assuming an anisotropic lineshape of the hyperfine couplings. Extra weak hyperfine couplings, unresolved in the CW EPR, were also included in the simulation. These probably correspond to hyperfine coupling in polymer which was undoubtedly present. The broad feature at low frequency is related to a mixture of fluorine $\left({ }^{19} \mathrm{~F}\right)$ and nitrogen $\left({ }^{14} \mathrm{~N}\right)$ contributions. The anisotropy and the unresolved nuclear quadrupole of the nitrogen couplings make the spectra difficult to interpret. Each ${ }^{1} \mathrm{H}$ contributes three sets of peaks to the spectrum times the number of ${ }^{1} \mathrm{H}$ 's present. This represents an enormous number of lines in one spectrum. Obviously, they cannot all be assigned from this broad unresolved powder pattern. Almost axial tensors were assumed (see Supporting Information). However, it should be noted that it may well be possible to simulate these spectra with other parameter sets. The experimental Davies ENDOR data support the CW EPR data in confirming the magnitudes of the hyperfine couplings and the nitrogen interactions. Further pulse techniques such as electron spin echo envelope modulation (ESEEM) and its multidimensional extension Hyscore would be required to get more insight into the nitrogen contribution. Regarding the ${ }^{19} \mathrm{~F}$ contribution; only the low-frequency part of the ${ }^{19} \mathrm{~F}$ coupling fits well with the experimental data. The ${ }^{19} \mathrm{~F}$ high-frequency line in our simulation is not consistent with the experimental spectrum, which suggests that the latter might be highly asymmetric. Such situations have been previously reported in other studies where it was shown that this could be related to the relaxation time. Sometimes relaxation processes can lead to a partial saturation in the nuclear transitions such that the observed signal is the result of a transition in one manifold only [34]. Partial saturation may explain the absence of the ${ }^{19} \mathrm{~F}$ high-frequency line in our spectrum.

\section{DFT computations of radical cation properties}

Quantum chemical calculations were carried out with the Gaussian 03 programme package [35,36]. Density functional theory with the UB3LYP functional was employed. The equilibrium geometries were fully optimised with respect to all geometric variables, no symmetry being assumed either with the $6-31+\mathrm{G}(\mathrm{d}, \mathrm{p})$ basis set (dimers) or with the $6-31 \mathrm{G}(\mathrm{d})$ basis set (trimers). Isotropic EPR hfs were derived from computed Fermi contact integrals evaluated at the $\mathrm{H}$ - and $\mathrm{N}$-nuclei. The hfs were taken directly from the Gaussian output files and are shown in Table 1 and Table 2.

The optimum structures of the radical cations $\mathbf{1 7} \mathbf{a}^{+\bullet}$ and $\mathbf{1 7 \mathbf { b } ^ { + }}$ their associated SOMOs are shown in Figure 8.

The $\mathrm{C}-\mathrm{NH}$ bond lengths in radical cation $\mathbf{1 7 \mathbf { a } ^ { + \bullet }}(1.40$ and 1.38 $\AA)$ and $\mathbf{1 7} \mathbf{b}^{+\bullet}(1.38,1.39 \AA)$ indicated significant double bond character. The $\mathrm{CNC}$ angles in $\mathbf{1 7 \mathbf { a } ^ { + }}{ }^{\boldsymbol{\bullet}}$ and $\mathbf{1 7 \mathbf { b } ^ { + }}$ were 128.9 and $131.6^{\circ}$, showing significant widening from trigonal. The aromatic rings in all the structures were twisted significantly out of co-planarity. As might be expected on steric grounds, this increased in the dimers as the substitution site moved from the 4- to the 3- to 2-position. For example, the computed dihedral angles between the rings increased from 26.8 to 30.7 to 39.0 in the series $4-\mathrm{MeO}-\mathbf{1 1} \mathbf{b}^{+}$, $3-\mathrm{MeO}-\mathbf{1 7} \mathbf{a}^{+\bullet}$ and $2-\mathrm{MeO}-\mathbf{1 7} \mathbf{b}^{+}$, respectively. It seems that a compromise was reached in which the repulsive steric interaction between substituents of neighbouring rings was balanced against the stabilising effect from conjugation of the $\pi$-systems. The SOMOs depicted in Figure 8 show that there was still sufficient orbital overlap in the linear and angular dimer and trimer radical cations to support lengthy $\pi$-systems extending over all the rings and $\mathrm{N}$-atoms. This is in accordance with the EPR spectroscopic data, that show extensive delocalisation of the unpaired electron in dimer and trimer radical cations. The computed hfs in Table 1 and Table 2 show reasonable correspondence with the experimentally observed values.

\section{Conclusion}

Literature reports show that anilines can easily be oxidised to the corresponding resonance-stabilised radical cations, which can couple with more aniline to afford very persistent radical cation dimers $[37,38]$. The generation of these radical cations depends critically on the reaction conditions, in particular on the degree of protonation, which can facilitate electron transfer (ET) $[39,40]$. It has also been reported that electrochemical oxidation of aromatic amines can generate the same radical cations which can polymerise giving oligo- and poly-anilines [41]. In view of the fact that product analyses [31] identified aniline amongst the products from $\mathbf{1}$ and anisole amongst the products from 2 , it seems probable that the aromatic amines are the precursors of the dimer and trimer species.

A possible mechanism for production of anilines from the aromatic azides is set out in Scheme 4. Coordination of the metal halide to the starting azide should produce the Lewis base-acid adduct $\mathbf{1 2}$ that could undergo reduction by ET from more azide to afford, after nitrogen loss, the metal-coordinated aminyl radical 13 together with the $\mathrm{ArN}_{3}{ }^{+}$radical cation. Aminyl radical 13 could then abstract an $\mathrm{H}$-atom from solvent $\mathrm{RH}$ (or from $\mathrm{HMCl}_{2}$ when the metal hydrides were used) with the production of metal-coordinated amine 14. The latter can then pick up a proton to produce an aromatic amine and regenerate the metal halide. The reason 4-azidobenzonitrile 7 did not react with any of the group 13 metal chlorides may well be that the ET step $\mathbf{1 2} \rightarrow \mathbf{1 3}$ was inhibited by the presence of the electron acceptor $\mathrm{CN}$ group. 


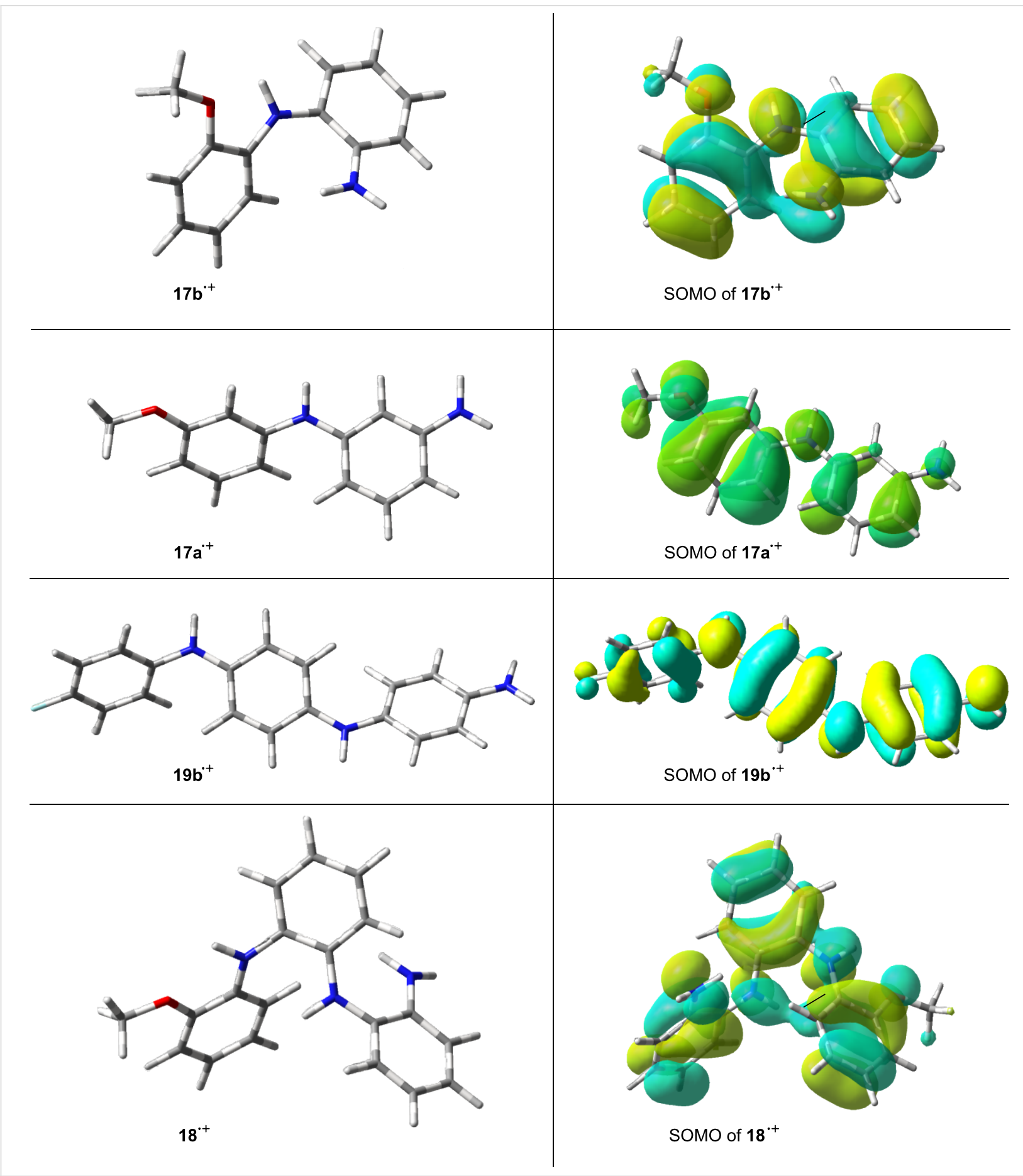

Figure 8: DFT structures and SOMOs for dimer and trimer radical cations.

Several mechanisms have been proposed in the literature for the formation of 'dimers' from anilines. These include [42-44]: (i) initial formation of the radical cation $\mathrm{ArNH}_{2}{ }^{+}$which then couples with more aniline and forms the 4-aminodiaryl amine radical cation after loss of $\mathrm{HX}$ and (ii) formation of the aniline radical $\mathrm{ArNH}^{\circ}$, which couples with $\mathrm{ArNH}_{3}{ }^{+}, \mathrm{ArNH}_{2}$ or $\mathrm{ArNH}_{2}{ }^{+\bullet}$. A plausible mechanism for formation of the dimer and trimer radical cations we observed is shown in Scheme 5 for the case of 2-methoxyaniline.

Ipso attack by radical 13a on the aniline would lead to the production of delocalised radical 15. Elimination of $\mathrm{MeOMCl}_{3}{ }^{-}$ would then yield radical 16, which, on protonation, would afford the observed long-lived dimer radical cations $17^{+}$. Of 


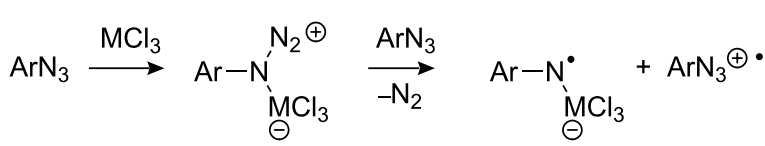

$$
\begin{aligned}
& 12 \\
& 13 \\
& \mathrm{RH} \downarrow \\
& \mathrm{MCl}_{3}+\mathrm{Ar}-\mathrm{NH}_{2} \stackrel{\mathrm{H}^{\oplus}}{\longleftarrow} \quad \mathrm{Ar}-\underset{\Theta}{\mathrm{NH}}
\end{aligned}
$$

Scheme 4: Possible mechanism of formation of aromatic amines.

course, proton transfer could occur earlier in the reaction, such that coupling takes place with the anilinium cation instead. Trimer $\mathbf{1 8}^{+}$could be produced by coupling of $17^{+}$with more 13a followed by a similar sequence of steps. The trimer could then grow into oligomer and polymer by a succession of such coupling reactions.

In general, the aromatic azides appeared to react most rapidly with $\mathrm{AlCl}_{3}$ but this reagent tended to generate much polymer. $\mathrm{InCl}_{3}$ was the least reactive group 13 halide such that no reac-<smiles>COc1ccccc1N(C)CCOC(C)(C)C</smiles><smiles>COc1ccccc1Nc1ccccc1N</smiles>

17<smiles></smiles><smiles>CC[C@H](C)COc1ccccc1Nc1ccccc1N</smiles><smiles>C=C[CH]C</smiles>

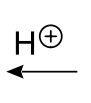<smiles>COc1ccccc1/N=C1/C=C=C=CC1N</smiles>

16
Scheme 5: Possible mechanism for dimer and trimer formation. tion was observed with $\mathrm{PhN}_{3}$ and very little reaction occurred with the 3 -methoxyazide $4 . \mathrm{GaCl}_{3}$ and $\mathrm{HGaCl}_{2}$ were the best promoters. The dimers were the main products from reactions of excess 1 and $\mathbf{2}$ with $\mathrm{GaCl}_{3}$ such that the process could have synthetic potential. In general, the $\mathrm{GaCl}_{3}$ - and $\mathrm{HGaCl}_{2}$ promoted reactions were also best for spectroscopic studies because they gave the most intense and well-resolved spectra of $\left.[\mathrm{ArNHArNH}]_{2}\right]^{+\bullet}$ and/or $\left\{[\mathrm{ArNH}]_{2} \mathrm{ArNH}_{2}\right\}^{+\bullet}$ with the narrowest line widths.

\section{Experimental}

EPR and ENDOR spectroscopy. EPR spectra were obtained with a Bruker EMX X-Band 10/12 spectrometer fitted with a rectangular ER4122 SP resonant cavity and operating at 9.4 $\mathrm{GHz}$ with $100 \mathrm{kHz}$ modulation. An aliquot $(\sim 0.1 \mathrm{~mL})$ of the reaction mixture from each aromatic azide and the metal chloride in $\mathrm{CH}_{2} \mathrm{Cl}_{2}$ /pentane or $\mathrm{CH}_{3} \mathrm{CN}$ solution was placed in a 1 $\mathrm{mm}$ o.d. quartz capillary tube, de-aerated by bubbling nitrogen for $20 \mathrm{~min}$ and transferred to the resonant cavity. Spectra were examined at several temperatures but generally best resolution and signal intensity were obtained at around $300 \mathrm{~K}$. Most of the EPR spectra were recorded with $2.0 \mathrm{~mW}$ power, 1.0-0.2 $G_{\mathrm{pp}}$ modulation intensity and a gain of $\sim 10^{6}$. In all cases where spectra were obtained, hfs were assigned with the aid of computer simulations using the Bruker SimFonia and NIEHS Winsim2002 software packages.

Pulsed EPR and ENDOR were performed using a pulsed EPR $\mathrm{X}$-band spectrometer (Bruker Elexsys E580) equipped with a Dice-ENDOR accessory, a radio frequency (rf) amplifier and a dielectric-ring ENDOR resonator (Bruker EN4118X-MD-4W1). Samples were maintained at $50 \mathrm{~K}$ using liquid helium in an Oxford CF-935 cryostat. Field-swept electron spin echo (ESE) spectra were recorded using a two-pulse ESE sequence while ESE-ENDOR experiments were carried out using Davies three-pulse sequence $\pi-T-\pi / 2-\tau-\pi$-echo with a selective rf pulse of variable frequency applied during time $T$. The pulse lengths used were 128 and $256 \mathrm{~ns}$ for $\pi / 2$ and $\pi$ respectively, and $10 \mu \mathrm{s}$ for the $\pi$-rf pulse. ENDOR data were processed and simulated using the EasySpin package (freeware from http:// www.easyspin.org/).

DFT calculations. All computations were done with the Gaussian 03W programme package (Version 6.1.0.0) [35]. Geometries were optimised at the UB3LYP/6-31+G(d,p) level [45] (dimers) and the UB3LYP/6-31G(d) level (trimers) and single point calculations at these geometries with a triple zeta quality basis set $(6-311++\mathrm{G}(\mathrm{d}, \mathrm{p}))$ were used to predict isotropic EPR hfs. The DGTZVP basis set, similar to that recommended by Schäfer et al. [46], was also employed for some computations. 
General procedure for the reaction of aryl azides with indium trichloride. The starting azide $(1 \mathrm{mmol})$ was added at $0{ }^{\circ} \mathrm{C}$ to an acetonitrile solution of indium trichloride $(1.1 \mathrm{mmol})$ in $\mathrm{DCM}(4 \mathrm{~mL})$ and stirred for $5 \mathrm{~min}$ at $0{ }^{\circ} \mathrm{C}$. Gas was evolved and the solutions took on a dark blue or violet colour. The resulting solutions were rapidly transferred into a quartz capillary tube and purged with nitrogen for few minutes. The tube was sealed and placed in the EPR resonant cavity. Spectra were recorded at several different temperatures. Some samples were photolysed with a $500 \mathrm{~W}$ super pressure $\mathrm{Hg}$ arc.

General procedure for the reaction of aryl azides with dichloroindium hydride. The starting azide $(1 \mathrm{mmol})$ was added at $0{ }^{\circ} \mathrm{C}$ to an acetonitrile solution of dichloroindium hydride $(1.1 \mathrm{mmol})$, generated in situ by stirring under an argon atmosphere anhydrous indium trichloride (243 mg, $1.1 \mathrm{mmol}$, previously dried by heating at $130{ }^{\circ} \mathrm{C}$ under argon for $1 \mathrm{~h}$ ) and triethylsilane $(177 \mu \mathrm{L}, 1.1 \mathrm{mmol})$ in $\mathrm{ACN}(4 \mathrm{~mL})$ for $5 \mathrm{~min}$ at $0{ }^{\circ} \mathrm{C}$ [47]. The resulting solution was rapidly transferred into a quartz capillary tube and nitrogen was bubbled inside for few minutes. The tube was sealed and placed in the EPR cavity. Spectra were recorded at several different temperatures. Some samples were photolysed with a $500 \mathrm{~W}$ super pressure $\mathrm{Hg}$ arc. Selected samples were given an aqueous work-up with $\mathrm{NaHCO}_{3}$ followed by extraction with diethylether. In each case the corresponding aromatic amine was identified by comparison with literature data.

General procedure for the reaction of aryl azides with $\mathbf{A l C l}_{3}$. Aluminium trichloride $(1.1 \mathrm{mmol})$ was dried under reduced pressure at $25^{\circ} \mathrm{C}$ for $1 \mathrm{~h}$. Then DCM $(3 \mathrm{~mL})$ was added and a DCM solution of the azide $(1 \mathrm{mmol}$ in $1 \mathrm{~mL})$ was introduced at rt. Gas was evolved, sometimes violently, and dark blue or violet colours developed. The resulting solution was then transferred to a capillary quartz tube and purged with nitrogen. The capillary was sealed and several EPR spectra were run at different temperatures. Product analysis was performed by quenching the reaction with an aqueous solution of $\mathrm{NaOH}$ and extracting with DCM. The mixtures were analysed by GC-MS and, when possible, by ${ }^{1} \mathrm{H}$ NMR and ${ }^{13} \mathrm{C}$ NMR spectroscopy.

General procedure for the reaction of aryl azides with $\mathbf{G a C l}_{3}$. A pentane solution of gallium trichloride $(0.55 \mathrm{~mL}$ of $0.5 \mathrm{M} ; 0.28 \mathrm{mmol})$ was added under a nitrogen atmosphere to a DCM solution of the azide $(0.25 \mathrm{mmol}$ in $4 \mathrm{~mL})$ at rt. Gas was evolved and an intense blue or violet colour developed. The resulting solution was then transferred into a capillary quartz tube and purged with nitrogen. The capillary was sealed, and the sample was analysed by EPR spectroscopy at several different temperatures. Products analysis was performed as above.

Ethyl 5-azidopentanoate (9) [48] was prepared by treatment of the corresponding alkyl bromide with sodium azide in DMSO [49]; IR ( $\left.v_{\max }, \mathrm{CHCl}_{3}\right), 1718(\mathrm{CO})$ and $2092\left(\mathrm{~N}_{3}\right) \mathrm{cm}^{-1}$; ${ }^{1} \mathrm{H}$ NMR $(400 \mathrm{MHz}) \delta 1.24(\mathrm{t}, J=7.2 \mathrm{~Hz}, 3 \mathrm{H}), 1.54-1.77(\mathrm{~m}$, $4 \mathrm{H}), 2.32(\mathrm{t}, J=6.9 \mathrm{~Hz}, 2 \mathrm{H}), 3.28(\mathrm{t}, J=6.6 \mathrm{~Hz}, 2 \mathrm{H}), 4.13$ (q, $J$ $=7.2 \mathrm{~Hz}, 2 \mathrm{H})$.

Aromatic azides 1-8 were prepared by standard diazotisation of the corresponding anilines followed by treatment with sodium azide, and were identified by comparison with literature data: phenyl azide (1) [50], 1-azido-4-methoxybenzene (2) [48], 1-azido-3-methoxybenzene (4) [51], 1-azido-2-methoxybenzene (5) [48], 1-azido-4-fluorobenzene (6) [48], 4-azidobenzonitrile (7) [52] and 2-azidonaphthalene (8) [53]. 2,3,5,6-Tetradeuterio-4-methoxyphenyl azide (3) was prepared by diazotisation of 2,3,5,6-tetradeuterio-4-methoxyaniline, derived in turn from the reaction of 3,5-dideuterio-4methoxyaniline hydrochloride with boiling $\mathrm{D}_{2} \mathrm{O}$ for 4 days in a sealed tube [31].

\section{Supporting Information}

Supporting information features general procedures, EPR spectra from azides $\mathbf{4}$ and $\mathbf{5}$, deconvolution of ENDOR spectrum from azide 6, Cartesian coordinates for DFT-computed structures of dimer and trimer radical cations.

\section{Supporting Information File 1}

EPR and pulsed ENDOR study of intermediates

from reactions of aromatic azides with

group 13 metal trichlorides

[http://www.beilstein-journals.org/bjoc/content/

supplementary/1860-5397-6-84-S1.pdf]

\section{Acknowledgements}

We thank EaStChem and the EPSRC (UK Basic Technology Programme grant GR/S85726/01) for financial assistance. We also acknowledge financial support from MIUR, Italy (2008 PRIN funds for 'Properties and reactivity of free radicals in complex environments and their role in oxidative processes and in organic synthesis').

\section{References}

1. Takami, K.; Yorimitsu, H.; Oshima, K. Org. Lett. 2002, 4, 2993-2995. doi:10.1021/ol026401w 
2. Ichinose, Y.; Nozaki, K.; Wakamatsu, K.; Oshima, K.; Utimoto, K. Tetrahedron Lett. 1987, 28, 3709-3712. doi:10.1016/S0040-4039(00)96363-9

3. Nozaki, K.; Ichinose, Y.; Wakamatsu, K.; Oshima, K.; Utimoto, K. Bull. Chem. Soc. Jpn. 1990, 63, 2268-2272. doi:10.1246/bcsj.63.2268

4. Taniguchi, M.; Nozaki, K.; Miura, K.; Oshima, K.; Utimoto, K. Bull. Chem. Soc. Jpn. 1992, 65, 349-353. doi:10.1246/bcsj.65.349

5. Chatgilialoglu, C.; Ballestri, M.; Ferreri, C.; Vecchi, D. J. Org. Chem. 1995, 60, 3826-3831. doi:10.1021/jo00117a038

6. Schiefer, M.; Reddy, N. D.; Ahn, H.-J.; Stasch, A.; Roesky, H. W.; Schlicker, A. C.; Schmidt, H.-G.; Noltemeyer, M.; Vidovic, D. Inorg. Chem. 2003, 42, 4970-4976. doi:10.1021/ic0342806

7. Takami, K.; Mikami, S.; Yorimitsu, H.; Shinokubo, H.; Oshima, K. J. Org. Chem. 2003, 68, 6627-6631. doi:10.1021/jo0344790

8. Mikami, S.; Fujita, K.; Nakamura, T.; Yorimitsu, H.; Shinokubo, H.; Matsubara, S.; Oshima, K. Org. Lett. 2001, 3, 1853-1855. doi:10.1021/ol015904j

9. Takami, K.; Usugi, S.-I.; Yorimitsu, H.; Oshim, K. Synthesis 2005, 5, 824-839. doi:10.1055/s-2005-861846

10. Balch, A. L.; Latos-Grazynski, L.; Noll, B. C.; Phillips, S. L. Inorg. Chem. 1993, 32, 1124-1129. doi:10.1021/ic00059a017

11. Lee, K. E.; Higa, K. T. J. Organomet. Chem. 1993, 449, 53-59. doi:10.1016/0022-328X(93)80106-L

12. Yasuda, M.; Miyai, T.; Shibata, I.; Baba, A.; Nomura, R.; Matsuda, H. Tetrahedron Lett. 1995, 36, 9497-9500. doi:10.1016/0040-4039(95)02057-8

13. Miyai, T.; Inoue, K.; Yasuda, M.; Baba, A. Synlett 1997, 6, 699-700. doi:10.1055/s-1997-3275

14. Miyai, T.; Inoue, K.; Yasuda, M.; Shibata, I.; Baba, A. Tetrahedron Lett. 1998, 39, 1929-1932. doi:10.1016/S0040-4039(98)00050-1

15. Inoue, K.; Sawada, A.; Shibata, I.; Baba, A. J. Am. Chem. Soc. 2002, 124, 906-907. doi:10.1021/ja017537c

16. Hayashi, N.; Shibata, I.; Baba, A. Org. Lett. 2004, 6, 4981-4983. doi:10.1021/ol047849v

17. Benati, L.; Bencivenni, G.; Leardini, R.; Minozzi, M.; Nanni, D.; Scialpi, R.; Spagnolo, P.; Zanardi, G.; Rizzoli, C. Org. Lett. 2004, 6, 417-420. doi:10.1021/ol036268n

18. Benati, L.; Bencivenni, G.; Leardini, R.; Minozzi, M.; Nanni, D.; Scialpi, R.; Spagnolo, P.; Zanardi, G. J. Org. Chem. 2005, 70, 3046-3053. doi:10.1021/jo0478095

19. Benati, L.; Bencivenni, G.; Leardini, R.; Minozzi, M.; Nanni, D.; Scialpi, R.; Spagnolo, P.; Zanardi, G. J. Org. Chem. 2006, 71, 434-437. doi:10.1021/jo0521697

20. Benati, L.; Bencivenni, G.; Leardini, R.; Minozzi, M.; Nanni, D.; Scialpi, R.; Spagnolo, P.; Zanardi, G. J. Org. Chem. 2006, 71, 5822-5825. doi:10.1021/jo060824k

21. Bencivenni, G.; Lanza, T.; Leardini, R.; Minozzi, M.; Nanni, D.; Spagnolo, P.; Zanardi, G. J. Org. Chem. 2008, 73, 4721-4724. doi:10.1021/jo800453z

22. Lanza, T.; Leardini, R.; Minozzi, M.; Nanni, D.; Spagnolo, P.; Zanardi, G. Angew. Chem., Int. Ed. 2008, 47, 9439-9442. doi:10.1002/anie.200804333

23. Minozzi, M.; Nanni, D.; Spagnolo, P. Chem.-Eur. J. 2009, 15, 7830-7840. doi:10.1002/chem.200802710

24. Baguley, P. A.; Walton, J. C. Angew. Chem., Int. Ed. 1998, 37, 3072-3082.

doi:10.1002/(SICI)1521-3773(19981204)37:22<3072::AID-ANIE3072>3 .0.CO;2-9

25. Studer, A.; Amrein, S. Synthesis 2002, 7, 835-849. doi:10.1055/s-2002-28507
26. Darmency, V.; Renaud, P. Top. Curr. Chem. 2006, 263, 71-106. doi:10.1007/128_030

27. Walton, J. C. Top. Curr. Chem. 2006, 264, 163-200. doi:10.1007/128_021

28. Walton, J. C.; Studer, A. Acc. Chem. Res. 2005, 38, 794-802. doi:10.1021/ar050089j

29. Benati, L.; Bencivenni, G.; Leardini, R.; Nanni, D.; Minozzi, M.; Spagnolo, P.; Scialpi, R.; Zanardi, G. Org. Lett. 2006, 8, 2499-2502. doi:10.1021/ol0606637

30. Bencivenni, G.; Lanza, T.; Minozzi, M.; Nanni, D.; Spagnolo, P.; Zanardi, G. Org. Biomol. Chem. 2010, 8, 3444-3450. doi:10.1039/c001848a

31. Bencivenni, G.; Cesari, R.; Nanni, D.; El Mkami, H.; Walton, J. C. Org. Biomol. Chem. 2010. doi:10.1039/C0OB00084A

32. Davies, E. R. Phys. Lett. A 1974, 47, 1-2. doi:10.1016/0375-9601(74)90078-4

33. Van Doorslaer, S.; Vinck, E. Phys. Chem. Chem. Phys. 2007, 9, 4620-4638. doi:10.1039/b701568b

34. Epel, B.; Manikandan, P.; Kroneck, P. M. H.; Goldfarb, D. Appl. Magn. Reson. 2001, 21, 287-297. doi:10.1007/BF03162408

35. Gaussian 03, Revision A.1; Gaussian, Inc.: Pittsburgh, PA, 2003.

36. Barone, V. In Recent Advances in Density Functional Theory; Chong, D. P., Ed.; World Scientific Publishing Co.: Singapore, 1996. [for the basis set B3LYP/EPRiii//B3LYP/6-31G(d)].

37. Forrester, A. R.; Hay, J. M.; Thomson, R. H. Organic Chemistry of Stable Free Radicals; Academic Press: New York, 1968; pp 247-268. Chapter 6.

38. Male, R.; Allendoerfer, R. D. J. Phys. Chem. 1988, 92, 6237-6240. doi:10.1021/j100333a014

39. Wolf, J. F.; Forbes, C. E.; Gould, S.; Shacklette, L. W. J. Electrochem. Soc. 1989, 136, 2887-2891. doi:10.1149/1.2096307

40. Wienk, M. M.; Janssen, R. A. J. J. Am. Chem. Soc. 1996, 118, 10626-10628. doi:10.1021/ja9616591

41. Petr, A.; Dunsch, L. J. Phys. Chem. 1996, 100, 4867-4872. doi:10.1021/jp952965o

42. Petr, A.; Dunsch, L. J. Electroanal. Chem. 1996, 419, 55-59. doi:10.1016/S0022-0728(96)04861-9

43. Simon, P.; Farsang, G.; Amatore, C. J. Electroanal. Chem. 1997, 435, 165-171. doi:10.1016/S0022-0728(97)00284-2

44. Goto, M.; Otsuka, K.; Chen, X.; Tao, Y.; Oyama, M. J. Phys. Chem. A 2004, 108, 3980-3986. doi:10.1021/jp035579c

45. Becke, A. D. J. Chem. Phys. 1993, 98, 5648-5652. doi:10.1063/1.464913

46. Schäfer, A.; Horn, H.; Ahlrichs, R. J. Chem. Phys. 1992, 97, 2571-2577. doi:10.1063/1.463096

47. Hayashi, N.; Shibata, I.; Baba, A. Org. Lett. 2004, 6, 4981-4983. doi:10.1021/ol047849v

48. Khoukhi, N.; Vaultier, M.; Carrié, R. Tetrahedron 1987, 43, 1811-1822. doi:10.1016/S0040-4020(01)81492-7

49. L'abbé, G.; Sannen, I.; Dehaen, W. J. Chem. Soc., Perkin Trans. 1 1993, 27-29. doi:10.1039/P19930000027

50. Huber, M.-L.; Pinhey, J. T. J. Chem. Soc., Perkin Trans. 1 1990, 721-722. doi:10.1039/P19900000721

51. Di Nunno, L.; Scilimati, A. Tetrahedron 1986, 42, 3913-3920. doi:10.1016/S0040-4020(01)87546-3

52. Nicolaides, A.; Enyo, T.; Miura, D.; Tomioka, H. J. Am. Chem. Soc. 2001, 123, 2628-2636. doi:10.1021/ja003709e

53. Forster, M. O.; Fierz, H. E. J. Chem. Soc., Trans. 1907, 91 , 1942-1953. doi:10.1039/СT9079101942 


\section{License and Terms}

This is an Open Access article under the terms of the Creative Commons Attribution License

(http://creativecommons.org/licenses/by/2.0), which permits unrestricted use, distribution, and reproduction in any medium, provided the original work is properly cited.

The license is subject to the Beilstein Journal of Organic Chemistry terms and conditions:

(http://www.beilstein-journals.org/bjoc)

The definitive version of this article is the electronic one which can be found at:

doi:10.3762/bjoc. 6.84 